This is an Author's Accepted Manuscript of an article published in the Historical Journal of Film, Radio and Television 32, 2 (2012): 245-65, (c) Taylor \& Francis 2012.

Available online at http://www.tandfonline.com/loi/chjf20

DOI: http://dx.doi.org/10.1080/01439685.2012.669887

\title{
A technicians' dream? The Critical Reception of 3-D Films in Britain
}

\author{
Keith M. Johnston \\ School of Film \& Television Studies \\ University of East Anglia \\ Norwich \\ Norfolk \\ NR4 7TJ
}

\begin{abstract}
Recent debates about the role of 3-D within cinema (and other media) have contained the traces of a largely anti-stereoscopic agenda that can be traced back to critical responses to 3-D in the 1950s. This article considers how British film reviews from the 1950s and 1980s established potent terms of discussion around the 3-D technology, its potential aesthetic development, and the role of stereoscopy within cinema. Exploring the parameters that the original reviewers set in place concerning the 3-D aesthetic, notably claims around realism, novelty, and gimmickry, the article argues that the language and terms of 1950s British film reviewers have worked to set an agenda that resonates through both the 1980s 3-D revival and modern day digital 3-D.
\end{abstract}


[T]he stereoscopic film never had artists to back it; it was only a technician's dream (Raymond Spottiswoode, 1951) ${ }^{1}$

Discussion of, or analysis of, stereoscopic 3-D technologies has been curiously absent from academic literature. ${ }^{2}$ Most film histories reduce 3-D to a brief aside about the 1950s (where it functions as a cautionary tale of a technological step too far), while the technology's continued presence through the following decades is rarely addressed within the academy, despite the recent expansion in 3-D film, television and other media. Historically, the most potent source of 3-D discourse and analysis has been found within film reviews, allowing newspapers, trade journals and magazines to define the parameters of the stereoscopic debate. These positions include business and economic merits, the assumed dissatisfaction of the cinema audience, accusations of gimmickry and repetitive aesthetic tropes, most often based around objects being thrown at the audience. ${ }^{3}$

Given those elements have defined the anti-stereoscopic agenda that has developed over the last six decades, this article will explore the foundations of that agenda through analysis of the main arguments and opinions expressed by British film critics in the 1950s, and the return (and re-emphasis) of those opinions in the 1980s 3-D revival. These moments of 'agenda-setting' in popular criticism will be shown to have defined 3-D as a novelty technology, not a source of art or creativity, a language that continues to recur in the modern period. ${ }^{4}$ The focus on a technological subject is a departure from those reception studies that focus on specific films, genres or directors, allowing the article to consider the role of British film reviewers, cultural critics and industry commentators in creating and reinforcing a particular agenda around 3-D technology. ${ }^{5}$ To paraphrase Barbara Klinger, the value in analysing film reviews (and 
reviewers) lies in establishing how language is mobilised to define and contain film technology in the wider culture; producing rhetoric that helps 'to establish the terms of discussion and debate. ${ }^{, 6}$ Moving from a specific film to a film technology, however, creates unique problems for the analysis of historical discourse, as such technologies have often been often overlooked in favour of more traditional tenets of film reviews such as 'plot and character, or regarded as a vulgar necessity in critical debates about motion picture art and popular culture, ${ }^{7}$ The rare times when technology has been heralded, the focus has been on the possible enhancements it can offer to realism or audience immersion. ${ }^{8}$ As this article will demonstrate, critical responses to the introduction and resurgence of 3-D have moved between these different camps, as commentators struggle to ascertain the aesthetic possibilities of the technology, consider its relationship with ideas around 'realism,' and make assumptions about audience dissatisfaction.

To explore how debates have been constructed around 3-D, the article intends to focus primarily on pre-digital stereoscopic technology, and its reception in mainstream British publications. In the two periods explored here, publications were chosen from across the political spectrum: 1950s reviews are taken from popular mass market titles such the Daily Mirror, Daily Express, Daily Mail, and the Daily Star, compared with more specialised titles such as the Financial Times, the Daily Telegraph and The Sunday Times, or the British Film Institute's publications Sight \& Sound and the Monthly Film Bulletin; to expand beyond any London metropolitan bias, reviews were also collected from Scottish publications the Edinburgh Evening Dispatch, the Daily Record, and the Glasgow Herald. The 1980s selection ranges across many of the same newspaper titles, but expands to include more specialist magazine or journal coverage in publications such as the Morning Star, New Statesman, Starburst and Films and 
Filming, alongside weekly listings magazines such as London's City Limits. While this entails a broad scope of titles and ideologies, it is essential in establishing the range of opinion on stereoscopic technology that developed across the political and cultural spectrum.

Highlighting the British experience also allows the article to contrast the reaction to British 3-D stereoscopic short films produced and exhibited in 1951-55 with the major American 3-D feature films released in 1953-55 and 1982-84 (representing the time periods when 3-D production and exhibition was most pronounced). ${ }^{9}$ As the first example of 3-D technology in Britain in the 1950s, these short films (which represented a wide range of 3-D approaches, covering documentary, animation, dramadocumentary, ballet, and commercial advertising) appeared to sit within the reliable, realist, documentary mode of British filmmaking. Yet they are also technologically advanced, visually innovative and spectacular: presenting a dichotomy that reviewers struggled with. Analysing the range of critical responses in the 1950s, notably around ideas of realism, aesthetics and long-term acceptance, allows the article to identify the dominant critical agenda that appeared across this range of disparate British publications and argue that such an agenda has influenced all subsequent discussions of 3-D technology, defining its place within cultural hierarchies of the film industry.

To illustrate how that initial critical response coloured later acceptance of 3-D filmmaking, the second half of the article moves to the 1980s 3-D revival. Despite the thirty year break in mainstream release, analysis of this period demonstrates a broad echo of the 1950s critical agenda, although with a limited number of new reviewer voices that suggest the potential for an expansion of dominant ideas. Using these two periods as the main source of evidence allows the article to initiate a 'reception trajectory' around stereoscopic technology that understands critical responses in both 
synchronic and diachronic terms, not simply restricted to one time period, but including a range of 'competing and opposite discourses [...] stretched out over several timeframes. ${ }^{10}$ As the conclusion will demonstrate in more depth, the critical response from these different periods is important because they reveal how key linguistic and rhetorical terms have shaped (and arguably limited) the broader understanding and discussion of 3-D film history, reaching 'a "final moment"' where the meaning and reputation of the technology may have become culturally consolidated. ${ }^{11}$ As the conclusion will suggest, the agenda set in these earlier time periods is clearly visible in modern reviews of digital 3-D technology, suggesting that this 'final moment' encourages repetition rather than reassessment of 3-D technology.

\section{'A New Window in Space for the Cinema': Britain, 3-D, and the 1950s}

In 1951, four short British 3-D films were screened as part of the 1951 Festival of Britain. ${ }^{12}$ These films (Now is the Time...to put on your glasses (Norman McLaren, NFBC/BFI; UK, 1951), Around is Around (McLaren, NFBC/BFI; UK, 1951), A Solid Explanation (Peter Bradford, Pathé Documentary Unit/BFI; UK, 1951) and Distant Thames / Royal River (Brian Smith, International Realist/BFI; UK, 1951) offered an innovative combination of animation, mock explanatory documentary and travelogue. ${ }^{13}$ While this flurry of British 3-D activity was new to British production, it was also the latest example of a wider interest in stereoscopy. Stereoscopic still cameras and viewers had been available to buy (and rent) from photographic shops throughout Britain, Europe and North America since the 1850s. While that extends the cultural understanding of three-dimensional photography outside the limits of this current article, it is worth noting that those stereoscopic photographs offered glimpses of known and unknown 'reality,' through images of distant lands and sights (the Grand 
Canyon, the Great Wall of China, Arab markets and souks, African villages), ‘celebrity’ photographs of figures such as Queen Victoria and Gypsy Rose Lee, and (for those who could afford it) family portraits. As Laura Burd Shiavo has demonstrated, the spectacular (and artificially created) nature of these images was subsumed by an emerging discourse that linked the technology (twin lenses and twineyed viewing apparatus) with the two eyes of a human being. ${ }^{14}$ This, in concert with stereoscopic advertising and popular commentary, emphasised realism over any inherent visual spectacle. Victorian comments on stereoscopic pictures noted that they allowed viewers to 'see things as they are in nature,' that stereoscopes presented 'all the objects in solid relief, as perfectly as if the landscape itself were spread out before it' and that it presented 'the world... in all its solidity and reality, as if we were looking out of a window.' ${ }^{15}$ The recurring linguistic elements of that popular discourse would recur when 3-D films were produced and exhibited throughout the $20^{\text {th }}$ century (and into the $21^{\text {st }}$ ): reality, a reflection of nature, a mechanical recreation of the optical properties of the eye itself, and the idea that such 'natural' and 'real' images were solid and substantial. $^{16}$

The first reviews of the 1951 'all-British' stereoscopic film technology described entertainment 'in a most life-like form,' displaying 'a very real feeling of surface texture' with water that 'really does look wet,' and featuring objects that 'looked so realistic you wanted to reach out and touch them. ${ }^{17}$ The continued emphasis on the reality (and solidity) of nature was enhanced by the choice of topics for two of the first British films: A Solid Explanation was an introductory comic documentary dominated by shots of animals at London Zoo. Although certain elements were used for spectacular purposes - a giraffe's head that 'thrust [...] out of the screen' or playful animals that caused the audience to 'recoil involuntarily before the sea lions' splash' - 
the emphasis remained on the realistic portrayal of nature made possible by the stereoscopic technology. ${ }^{18}$ The second documentary film, the Technicolor Distant Thames / Royal River, tended towards the landscape themes of earlier stereoscopic photography, featuring footage of a boat journey down the Thames, past Windsor Castle, to London's South Bank (where the Festival of Britain was taking place). With an emphasis on images of the riverside, green fields, and rural settings, the film was praised by critics in British publications such as The Listener for its realistic combination of colour and stereoscopy: featuring 'a depth and realism never before seen... [capturing] the loveliness of the English land,' the apparent realism created by 3D technology gave 'the impression of a mid-stream progress up the Thames on a bright sunny day.' 19

This discussion of 3-D films as offering reality would continue after the advent of the American 3-D feature film, but it is the British short documentaries that drew the most obvious focus on these elements. Yet the emphasis on realism in these early reviews began a trend that excluded art from discussions of stereoscopy (as noted in Raymond Spottiswoode's opening epigram). The other two 3-D films screened in 1951 (Now is the time (to put on your glasses) and Around is Around) were experimental animations by Scottish-Canadian artist Norman McLaren that made no concessions to debates around realism or the natural landscape. These animated films, featuring oscillating lines, stick figures, suns and moons (all painted directly onto the celluloid) offer a more emphatic foregrounding of the spectacular possibilities of stereoscopic composition. Yet their absence from most published reviews suggest they ran counter to two more acceptable discourses: one around stereoscopic realism and nature that had dominated for almost a hundred years, and the other around British cinema's reputation as a provider of documentary realism. ${ }^{20}$ The focus remained the traditional 
documentary projects: 3-D studies of a new oil refinery (Northern Towers, Roy Harris, Shell Film Unit/Stereo Techniques; UK, 1952), open cast mining (Sunshine Miners, J.D. Chambers, Stereo Techniques; UK, 1952) and London Airport (Air Junction, Anglo-Scottish/Stereo Techniques; UK, 1953). Those more spectacle-based or artistic projects based around animation (The Owl and the Pussycat, John Halas, Halas \& Bachelor/Stereo Techniques; UK, 1953), ballet (The Black Swan, Leonard Reeve, Anglo-Scottish/Stereo Techniques; UK, 1952) or drama-documentary (Vintage '28, Robert Angell, Film Partnership/Stereo Techniques; UK, 1953) were sidelined in critical commentary. ${ }^{21}$

The wider reception of these experimental 3-D films in 1950s Britain combined these ideas around realism with optimistic language about modernity and the future. 3 D (and the Telekinema itself) was described as 'a cinema-of-the-future' and 'futuristic': an emphasis on British cinema as modern and innovative. ${ }^{22}$ This tied in to the Festival's aim to present post-war Britain as a still-potent technological, engineering and artistic force within Europe and the world. However, this emphasis on modernity and innovation troubled specialist British film publications. Trade journals Kinematograph Weekly and Today's Cinema, along with fan magazine Picturegoer, took umbrage at 'less informed and responsible' national newspapers which reported on the exhibition of the stereoscopic shorts as a revolutionary British success rather than simply another step in film's stereoscopic history. ${ }^{23}$ This not only points to the tension that existed between industry journals and newspaper critics (contemporary editorials in such journals point to a strained relationship based around levels of knowledge and hierarchies of access) but also suggests that before these 3-D British shorts could even prove themselves, there was a critical row brewing over how British 3-D film related to the broader history of stereoscopic technology. ${ }^{24}$ 
Discussions of British 3-D remained contentious through the five months of the Telekinema's existence, and in the years that followed, with particular attention given to assessments of the technology for long-term use. One of British cinemas most celebrated producers, Sir Michael Balcon (head of Ealing Studios), commented that he was too 'busy surviving in two dimensions' to experiment with such technological novelty. ${ }^{25}$ The emphasis here is around the cost of technology over any inherent artistic merits or possibilities and, again, points to the difference in reporting style between newspapers and trade press. The latter regularly stated that 3-D technology was 'quite unsuitable for commercial application, ${ }^{26}$; and accused the British films of doing 'nothing to create a popular demand for the third dimension,' suffering from a 'lack of imagination,' and failing to give audiences 'an enhancement of the glamour and personality of their favourite stars. ${ }^{27}$ However, the popular success of these British films at the Telekinema, the 1951 Edinburgh Film Festival, and at a growing number of cinemas around the country, began to create more interest in potential commercial application of the technology in the mainstream press. $^{28}$

As more cinemas screened the films, review language began to move away from terms such as 'futuristic' and 'modern' towards less positive language such as 'novelty,' 'trickery' or 'gimmick.' While this tendency can be found in some original reports on the Telekinema, it becomes more prevalent in 1952-3: British short films are increasingly described as having 'novelty values,' while 'the novelty alone' of American 3-D features 'will attract the crowds'. ${ }^{29}$ Through such reviews, stereoscopic technology begins to be defined as a sideshow attraction, a transitory experience when compared to the normative (and culturally acceptable) example of the 2-D (or 'flat') narrative feature film. Describing the British 3-D short films as a novelty reduced them to the level of programme filler, a lesser component of the cinema's cultural hierarchy. 
As the Glasgow Herald noted, this novelty ensured 'the "shorts" were curiosities, fascinating glimpses into the future,' rather than dominant or central elements of the film landscape. ${ }^{30}$

The emphasis on novelty and gimmickry in both trade and popular press reviews was most often identified with previous technology and specific stylistic and aesthetic elements of the 3-D technology. The association with other processes was most commonly a link to synchronised sound, the last major technological revision of cinema at the levels of production and exhibition. As this conversion had been both costly (across the industry) and contentious (often seen as enforcing an American technology onto British films), the connection was used to fuel both optimistic and pessimistic depictions of 3-D. Reviewers of the British shorts stressed 3-D was 'only in the earliest of stages, comparable with the earliest sound pictures,' and that this was 'a period of transition for the technology. ${ }^{31}$ Reviews for the first American 3-D features initially echoed this approach: 3-D was 'going to be as vital as the switch from silent films to talkies,' while 3-D producers Warner Bros. had 'done for 3-D what they did for the talkies by making “The Jazz Singer”... [this film] will convince public and filmproducers alike that 3-D is the next step in the march of the movies. ${ }^{32}$

Despite recurring language that suggested 3-D technology was moving through a transitional period, a hierarchical split began to appear between popular appeal and critical acclaim, particularly around American feature films such as Bwana Devil (Arch Oboler, United Artists; US, 1952) and House of Wax (Andre de Toth, Warner Bros; US, 1953). The early British shorts were broadly seen as interesting novelties with limited commercial appeal, but the emphasis on their documentary elements effectively removed them from the commercial mainstream, retaining some aspect of the rarefied (and culturally valued) realm of British documentary realism. However, the American 
feature film was seen as more of a throwback, either to the days of synchronised sound, or even further back in film history. 3-D feature House of Wax went 'right back to the early days of cinema itself... [with] all the drama of the silent heyday,' 'an astonishing compound of penny dreadful and silent serial'; while the first batch of American 'deepies' offered 'a straight regression to the first serials. ${ }^{33}$ In place of a developmental model, where 3-D would (like synchronised sound) become more established and better used (artistically and technologically), these reviews assert the opposite: a return to the attraction-led world of early film (and associated trickery), to primitivism, and to less adult forms of cinema. It is first seen in a series of reviews in the Monthly Film Bulletin, where A Day in the Country (Lippert Pictures; US, 1953) is criticised as 'primitive alike in subject matter and technique' and House of Wax is described as 'a childish and inept piece of work. ${ }^{34}$ That trend was developed by Sunday Dispatch reviews that claimed ' $3-\mathrm{D}$ is still in its infancy, and we must forgive directors playing nursery games' and noted 3-D films indulging in 'the usual schoolboy trick of throwing things at the audience ${ }^{35}$ (my emphasis). Such reviews demonstrate critical tastemaking and agenda-setting at work: the repetition of language around juvenilia returned to concerns around larger issues of realism and the 'serious' cultural contributions films could make. Nothing 'childish,' or in its 'infancy,' could be taken seriously, or be regarded as an important element of cinema's continued artistic development.

The reception of 3-D technology had, therefore, turned almost wholly negative by late 1953 , where the perceived failures of the process began to outweigh any potential realist or artistic benefits. More specifically, issues around the 3-D aesthetic, the storytelling restrictions (or possibilities) of 3-D, the lack of serious artistic effort, and the wearing of polaroid glasses, became the dominant frame within which 3-D technology was judged, and ultimately found wanting. The historical echoes of this 
moment in the technology's reception trajectory cannot be emphasised strongly enough: every attempt to revive 3-D since 1955 has returned to these debates, to ideas around why the technology failed, what it was unable to do, and why it was never considered to be a serious addition to cinema's technological arsenal. A closer examination of these elements will allow later sections to demonstrate their potency throughout critical responses in the 1980s and beyond.

The discussion of 3-D aesthetics began with Raymond Spottiswoode's assertion that the third dimension gave directors the 'ability to control movement in space without loss of any of the cinema's known powers' and created 'an unlimited field for experiment. ${ }^{36}$ As noted above, commentary on the British 3-D films tended to focus on realism over its potential for artistry or spectacle: the introduction of American feature films was seen by reviewers as a shift too far in the other direction. The first American film, Bwana Devil, was described as 'only slightly helpful' in providing 'a guide to the potential of the stereoscopic technique,' offering 'intriguing possibilities' but emphasising novelty and slipping 'further from reality. ${ }^{37}$ The film's novelty values were seen as raising it above its 'leadenly paced story and general narrative incompetence' but it presented no evidence on which to judge 'the artistic possibilities' of $3-\mathrm{D} .^{38}$

The only positive aesthetic element that was focused on by critics in the American 3-D features echoes that identified in earlier stereoscopic media: landscape. Bwana Devil featured 'four or five glorious tantalising shots of river and rock and jungle plain.... [3-D] makes one truly believe the jungle stretches right to the horizon; the eye sees wide distances'; Hondo (John Farrow, Warner Bros.; US, 1953) used 3-D to 'splendidly bring out the vastness of the landscape'; while The Charge at Feather River (Gordon Douglas, Warner Bros.; US, 1953) took 'full advantage of the mountain 
scenery' with 'thrilling natural backgrounds [that] are really seen to their best advantage. ${ }^{39}$ Mirroring the discourse around Victorian stereoscopy, the reviewers focus on the 3-D camera's ability to capture an element of reality, to offer a depth of vision, rather than to produce anything artistically new or different. In the British short films, landscape was an attraction in and of itself (Royal River, Sunshine Miners); in the American features it is a brief escape from juvenilia, with the 3-D landscapes delicately balanced between spectacle and realism.

Such positive comments on the 3-D aesthetic were rare, most often presented as scarce glimpses of potential, rather than dominant (or 'serious') contributions to a developing aesthetic. The dominant agenda within critical commentary on 3-D was the spectacle of items being thrown or pushed off screen at the audience:

The audience squirmed and laughed uncomfortably when charming heroine Barbara Balta pouted her lips somewhere at the back of the cinema to receive a kiss from the hero... women screamed when a lion came charging down the aisle, and many ducked as a native's spear whizzed from the screen into the auditorium (almost as many, in fact, as bent down to pick up the cigarettes which were "showered" from an introductory advertising short!) ${ }^{40}$

While depicting an audience immersed by the 3-D aesthetic (and, by extension, a suggestive combination of both stereoscopic realism and spectacle), this more 'intrusive' aspect of the 3-D aesthetic became a cause celebre for critics who were eager to brand the technology a retrograde step in cinema's development. Initially linked to the existing language around novelty and gimmickry, critical language began to describe the films as an attack on the viewer: 'a bombardment of everything from 
molten lead to baseballs'; 'Spears fly at you. Lions leap upon you.'; 'Objects whizz out of the screen'; 'it flings off the screen everything from tomahawks and flaming torches to torsos'; 'it hurls both itself and assorted objects right onto one's blinking 3-D eyes. ${ }^{, 41}$ This trend in the stereoscopic film was regularly repeated in British newspaper and trade reviews, featuring alongside the repetition of negative comments around polaroid glasses, and discussions of the inherently exploitative nature of 3-D film production. Yet, despite such complaints, critical commentary on it also necessarily stressed the apparent popularity of that aspect with the audience: they may have squirmed, shrieked and tried to pick up illusory cigarettes, but almost all critical descriptions of audiences for 3-D films have them reacting in positive ways to these 'intrusive' elements.

The range and variety of objects coming off the 3-D cinema screen was often seen in derogatory terms because of the alleged disruption of film narratives. Most critical reviews engage with story or narrative at some level, but it became a frequent concern for 3-D critics, who saw the illusion of visual immersion promised by stereoscopy (drawing viewers in through the layering of realistic landscapes and scenes) as anathema to cinema's existing ability to immerse audiences through narrative. Bwana Devil was (again) the initial focus of such debates, with reviews uncertain whether 3-D would be able to increase 'the camera's narrative power' or if it would prove restrictive. ${ }^{42}$ Reviewers regularly emphasised that while ' 3 -D has much to commend it, good film stories are still the first essential. ${ }^{43}$ The release of each new 3-D feature became another opportunity to establish this binary between the novelty of stereoscopic visual spectacle and the importance of traditional narrative techniques (again, a debate between gimmickry and serious entertainment), with critics noting that when reviewing 3-D films 'it seems almost inconsequent to mention the word "story", 44 
Newspaper critics' dismissal of novelty aspects of the 3-D aesthetic reached apotheosis around the film Inferno (Roy Ward Baker, $20^{\text {th }}$ Century Fox; US, 1953), Fox's only foray into 3-D film production. Produced just before Fox made the decision to film all future productions in its widescreen process CinemaScope, Inferno became the focus of British anti-3-D criticism in late 1953 when it was announced that most cinemas would see the feature in a 2-D version. Numerous articles stated that this decision was a direct response to critical opprobrium of 3-D technology, painting critics as gatekeepers of both critical taste-making and industry policy. Reviewers congratulated themselves on doing cinemagoers 'a good turn' by sticking to their guns and demanding the end of three-dimensional films: while the decision to release Inferno as a 'flattie' in most British cities was painted as a victory for good films over novelty (Inferno is a 'first-rate triangular drama' when it remains 'on the screen'), and for their own role as guardians of serious cinema. ${ }^{45}$

Although Inferno was not the end of 3-D films in British cinemas (American features continued to be released until late 1954) the debate did encapsulate one final aspect of critical discussions around the 3-D aesthetic. During the run up to the release of Inferno, there was a growing opinion that very little was lost if a 3-D film was shown in a 'flat' 2-D format. This opinion was supported by the release of features that had been released in 3-D in America, but reached Britain as 'flatties': Wings of the Hawk (Budd Boetticher, Universal International; US, 1953) was described as 'originally made in 3-D but... effective enough with standard equipment,' while reviews of Gog (Herbert L. Strock, Ivan Tors Productions; US, 1954), Miss Sadie Thompson (Curtis Bernhardt, Columbia Pictures; US, 1954) and The French Line (Lloyd Bacon, RKO; US, 1954) make no reference to their stereoscopic roots. ${ }^{46}$ Inferno itself is described as losing 'absolutely nothing' in 2-D, while Hondo (distributed in both 3-D and 2-D versions) 
'displays 3-D at its most negative' with 'the Western scenery... shown to its best advantage' in the 2-D print. ${ }^{47}$ Even the release of a 2-D Dial M for Murder (Alfred Hitchcock, Warner Bros.; US, 1954), produced by 'a master of the cinema like Hitchcock' produced little regret from critics that the 3-D element was missing. ${ }^{48}$ The attitude towards that film, and 3-D films in general, by July 1954 was summed up by The Sunday Times: 'Originally made in 3-D it is now shown nice and flat. ${ }^{, 49}$

The initial flurry of interest in 3-D (and the following sharp decline) among British critics can be read as an unwillingness to engage with the opportunities of the 3D aesthetic, and to insist on the maintenance of 'normative' film production: narrative, character, dialogue. The presence of elements seen as gimmicks or sideshow attractions (and the association reviewers drew with the 'primitive' birth of cinema, and the presound era) was presented by British critics as a distraction from what serious entertainment could offer, constantly branding 3-D as a juvenile, immature technology that had no place in cinema's current adult form. The critical insistence on representing 3-D in this way undercut any work 3-D filmmakers did to try and present stereoscopic technology as an increase in realistic mise-en-scene. The few moments of critical praise for the technology referred to its potential for realistic reproduction, most notably around landscape, but critics saw few sustained examples of that trend. However, the British critical response and reception of 3-D in the 1950s was not wholly restricted to the films or the 3-D aesthetic itself. There was one dominant area that coloured all reviews, and which presents a strong thread through the different eras identified here: the polaroid glasses, or special viewers, that were required to view any 3-D footage.

The glasses debate began with the first 3-D films screened in 1950s Britain, and newspaper reviews set an early negative tone: 'To get the three dimensional effect, I had to wear tinted stereoscopic spectacles... [which] is a strain. ${ }^{50}$ Despite one reference 
within the popular press to the glasses as 'magic spectacles,' a more disapproving (and prosaic) tone became common: a February 1952 report noted that one of the 'problems' with these films is 'the need for the audience to wear the special spectacles,' while another commentator described the polaroid glasses as 'a snag... [that] I have an idea people will soon tire of. ${ }^{51}$ This more strident tone became commonplace through 1953 and into 1954 as the American features continued to be exhibited: the glasses 'prove the bugbear'; had 'eyes streaming and aching'; made images 'dull and flatly photographed'; or made filmgoing 'a hateful experience. ${ }^{, 52}$ The need for such glasses also fuelled the larger debates discussed above: serious films don't need special glasses; the production of film-specific glasses served to highlight the novelty nature of the film being shown; and they created a barrier between audiences and full immersion in the screen narrative. Unlike other media such as photography or comic books, where the stereoscopic glasses were seen as a necessary part of the 3-D experience, British critics were anti-polaroid glasses (and the cheaper red-green anaglyph versions) from the very beginning. ${ }^{53}$

By mid-1954 3-D films were disappearing from British cinema screens, much to the delight of film reviewers and critics. While there are multiple causes behind this decline that extend beyond the film reviews (notably lack of product, falling attendance, and the growth of television) the agenda set by the critical dismissal of 3-D cannot be ignored. That rejection was fuelled by, and coalesced around, the elements identified here, particularly assumptions made about the technology's ability to produce 'realism,' issues around gimmickry or novelty elements overshadowing 'serious' entertainment, the lack of cohesive narratives, the uncertainty about what the 3-D aesthetic added to cinema, and the 'hateful' 3-D glasses. At the heart of popular 'talk' 
around 3-D technology in Britain in the 1950s, these elements would recombine and develop when 3-D returned to British cinemas in the 1980s. ${ }^{54}$

\section{'The Biggest Headache': 3-D in the 1980s}

For a time... the novelty alone will attract the crowds; we might then expect a great number of films to be produced in haste and rushed to the theatres in an effort to exploit the enthusiasm. Because of the deficiencies of these hastilyproduced films, we might then predict a flagging of public interest, a reaction of the industry against the technique, and a period of relative inactivity in the field, followed in time by a steady and constructive growth as the more farsighted producers perfect the medium. ${ }^{55}$

That declaration around 3-D's prospects was made by Edwin H. Land, President and Director of Research at Polaroid Corporation, in April 1953. From a $21^{\text {st }}$ century perspective, it appears oddly prescient, aware of the quick growth, reliance on novelty, and dip in audience interest that characterises the traditional understanding of the technology's failure in the 1950s. Despite Land's belief that 3-D would reach a period of 'steady and constructive growth,' where 'far sighted producers' would 'perfect the medium,' the evidence of British critical response to the process' return in 1982 suggests that the technology still lacked that moment of epiphany. 3-D had not been entirely dormant in the thirty years between 'booms,' being used for low budget genre films, arthouse offerings such as Flesh for Frankenstein (Paul Morrissey, Compagnia/Braunsberg; US/Italy, 1972), and one worldwide success in the soft-porn film The Stewardesses (Al Silliman Jr., Hollywood Films; US, 1969), which took 
'proper advantage' of the technology 'without literally hitting the audience in the face with the more obvious essentials' and aimed at a youth audience 'who don't even remember "Bwana Devil.",56 Yet the historical moment of 1982-84 offers a more useful case study than these largely standalone films, representing a higher frequency of 3-D films both at British cinemas and in popular reporting and reviewing, allowing wider trends in language and discourse to emerge, and critical agendas to become clear.

Unlike the 1950s, the early 1980s critical reception was not based entirely around newspapers and industry trade journals. Towards the end of the 1970s, a series of mass market cinema magazines began to appear in Britain, with many of them (Starburst, Cinefex, Starlog) focusing on popular genres such as science fiction and horror. Although these film magazines assumed a more cinema-savvy genre audience, they relied on the same kind of 'talk' around 3-D as critical sources from newspapers and specialised journals such as Monthly Film Bulletin, American Cinematographer and Sight and Sound. This section will, therefore, draw from a series of British publications where popular discourse around 3-D developed in this period: a series that takes in traditional newspaper critics, short pieces in weekly cultural 'what's on' magazines, and these new cinema magazines. This widening out of publications where audiences might encounter discussion of 3-D suggests a potential for a broader range of opinion, particularly around genre production. Yet this section demonstrates that the technology's reception trajectory was broadly coloured by the same popular 3-D touchstones: aesthetic issues, claims of novelty and juvenilia, and complaints about the polaroid glasses. As such, while analysis of this period reveals some expansion of the terms in which 3-D is received, it suggests that the technology remains corralled within the agendas set in the 1950s. Audiences may not have remembered Bwana Devil, but it is clear that critics did. 
3-D history is an important marker of critical perspective in many of these reviews, representing a moment where dominant ideas began to crystallise about what 1950s 3-D had produced and, notably, why it had failed. Some elements of this historical (re)positioning are familiar, with audience dissatisfaction and specific aesthetic approaches criticised; added to this was a new emphasis on 3-D and genre, and the idea of the original technology being primitive. One of the newer film magazines, Starburst, used the release of Parasite (Charles Band, Embassy Pictures'; US, 1982) as the basis of a (heavily illustrated) four-page article. Here, the history of 3D was retold in broad strokes, ignoring the British short films in favour of Bwana Devil and House of Wax, focusing on the process as a response to television, and reiterating audience frustration with things being thrown at them. ${ }^{57}$ A similar perspective can be found in a two-page colour feature in Film Review. Based around the release of Parasite and Comin' At Ya! (Ferdinando Baldi, CAU Productions; Italy, 1982), the article recites tales from the 1950s of notable genre entries and misaligned 3-D projection causing viewer eyestrain. ${ }^{58}$ Even at this early stage in the 1980 s 3-D boom, a familiar agenda becomes clear. Newspaper film reviews offered analogous definitions of 3-D film history: an 'early Fifties' response to 'the rising challenge of television', this was a 'brief boom... swept from the screens by another gimmick (CinemaScope),' with most films 'built around the visual thrills that the system offered. ${ }^{59}$ Taken together, these sources represent a solidification of 'official' 3-D history, defining 'old' 3-D around low budget genre films, gimmickry, audience complaints, competing technology, and 'the restricted filming techniques' of the $1950 \mathrm{~s} .{ }^{60}$

In one sense, this is standard film industry practice: an emphasis on the modern and improved version of an existing technology over previous iterations. This is not restricted to journalistic or critical articles. In production notes for Jaws 3-D (Joe Alves, 
Universal; US, 1983) 1950s 3-D equipment is described as 'cumbersome,' only capable of providing 'gimmicks.' The new 1980s system (here, Arrivision) is, by contrast, described as innovative, able to heighten the underwater drama of the blockbuster sequel. ${ }^{61}$ Arrivision technology features in several reviews: 'sharper, bright and altogether easier-on-the-eye image than any of its forerunners,' and 'the best 3-D process so far seen, giving an impression of real contour and reality. ${ }^{62}$ However, it was more common to find the underlying technology being referred to in a negative context: “"DimensionScope 3-D” delays the traditional 3-D viewer's headache until about an hour after the film's end. ${ }^{, 63}$ These examples of a specific 3-D process (Arrivision and Dimenscope) aside, individual 3-D processes were rarely the focus of critical attention across this period: references to technology were more likely to think of 3-D as one process (rather than several), emphasise its restrictions, or foretell its inevitable failure: 'it is difficult to believe that stereoscopy will ever revolutionise the cinema, if only because - as has been proved before - there is a severe limitation on the number of plots which will accommodate broom handles being poked into one's face. ${ }^{64}$ That notion of history repeating itself ('as has been proved before'), and the emphasis on aesthetic gimmicky and narrative, underpinned the critical repetition of the 1950s agenda: that 3-D technology was not the correct path for the future of cinema.

That tone of uncertainty and dismissal was set early on, with promotional and critical language around the first 3-D films released in 1980s Britain. Comin' at Ya and Parasite (a Western and a horror film) mirrored 1950s advertising policies that showed elements of the film coming 'off' the screen. 'Coming at you' quickly became the recurring 3-D aesthetic complaint among reviewers. Comin' at $Y a$ 'constantly assaulted' its audience 'with flying objects' including 'flaming arrows... [and] a pitchfork waving over the front stalls,' and contained a list of elements including 'a 
baby's bum, apple pairings, yo-yos, fruit bowls, swords, pikes, burning arrows, numerous nuts and vegetables, bats, [and] a bored Tonto lookalike. ${ }^{95}$ Parasite, meanwhile, was criticised by reviewers for relying on 'three dimensional grue and gore assaulting their eyeballs,' foregrounding 'stock 3-D shocks of reaching hands, pointing gun barrels. ${ }^{66}$ This early negative critical reaction to 1980 s 3-D continued with the bigger releases: Jaws 3-D offered an assault 'by 3-dimensional severed limbs and ravening snouts,' 'coming at you in shapes and scares that range from a frog leaping on to your lap to a syringe ejaculating into your eye or a tentacle tickling you under the chin. ${ }^{67}$ Amityville 3-D (Richard Fleischer, DeLaurentiis Entertainment; US, 1984), meanwhile, featured 'optical gimmicks' such as 'a frisbee [that] really does seem to be coming towards you. ${ }^{68}$ Critics, mirroring their 1950s counterparts (and reasserting the dominant ideas about 3-D history), found this specific 'coming at you' element of the 3-D film to be problematic, too obsessed with the novelty value and visual spectacle, and lacking any aesthetic claims to realism.

In fact, the idea of 3-D technology offering any form of realistic aesthetic was a notable absence from critical commentary of the 1980s. David Robinson's statement that Arrivision offered 'real contour and reality' is one of the few direct references to 3D's possible addition to cinematic representations of realism. ${ }^{69}$ Unlike the 1950 s, where the British short films had offered a bridge between stereoscopic realism and spectacle, or where the wide range of American 3-D films had offered a series of realistic landscapes, the short-lived 1980s boom, with its emphasis on independent, often low budget, American genre films, prevented any real discussion of this element. While several critics followed Robinson in noting the impressive quality of Jaws 3-D's imagery ('the sea bed [becomes] infinitely more beguiling ${ }^{\text {, }}$ ), the tendency was to identify the film's novelty 'coming at you' elements over any sense of enhanced 
realism: "viewers are treated to the sight of a decapitated head floating towards them., Such elements are never referred to as a realistic depiction of such imagery, always as a sense of spectacle and juvenile 'coming at you' visual trickery. Even Robinson's claim that Arrivision increased Jaws 3-D's sense of realism was tempered by other, more gimmick-laden elements of the film: the critic ultimately noted that the process was still 'waiting for better uses. ${ }^{, 72}$ As with the 1950s, the realist opportunities suggested by 3-D were overshadowed in critical opinion by a focus on the films' novelty values; 1980s critics saw only a limited potential for art and artistry in 3-D technology, with the process being pulled down by the filmmaker's obsession with technical gimmickry.

As discussed above, the term 'coming at you' worked to define 3-D technology in terms of a special effect: in particular, a technological gimmick that detracted from conventional or serious narratives. Comin' at $Y a$ had 'chopped logic... cheesy dialogue' and 'no plot'; Jaws 3-D was 'a gimmick,' 'like a visit to the theme park., 73 The link to theme parks (and fairground rides) has been a common one in critical dismissal of modern blockbuster films, suggesting the privileging of sensation and attraction over sustained or classical narrative engagement. Similarly, 1980s 3-D films were seen as offering 'very silly' stories, where 'depth effects' cannot 'make up for a screenplay that is packed with clichés. ${ }^{, 74}$ Again, this distanced the technology from value-laden cultural terms such as artistic or serious, linked once again with the idea of 'special effects' that had become so important in the George Lucas-Steven Spielberg-influenced Hollywood industry. Some critics noted a mild frustration that $3-\mathrm{D}$ could be 'a logical development of the medium' but that 'until filmmakers stop using it in crass and banal ways, it will remain the lowest form of cinematic life. ${ }^{75}$ By late 1983, at a time when only five or six 3-D films had been released in Britain, the fate of 3-D technology appeared to be sealed: too based around novelty, no strong alignment of 3-D effect with 
narrative, and with a genre and sequel focus that further removed it from serious artistic consideration.

Alongside these newspaper critics, writers from the newer film magazines were making similar observations about novelty and narrative, but from a different (and genre-specific) perspective. Rather than call for an end to 3-D production, these magazine critics were celebrating what 3-D could offer to such genre films (notably sequels), and the main negative note was that genre filmmakers were not pushing the technology to its extremes. A typical review of Friday the $13^{\text {th }}$ Part III (Steve Miner, Paramount; US, 1983), for example, might state how the film relied on the traditional gimmick of waving 'everyday objects... within inches of our noses,' but the 'added dimension does go a long way in making the routine suspense and scares more palatable'; equally, the film 'is in some ways very similar [but] different from its forerunners, and spectacularly so, in that it's been shot in 3-D. ${ }^{76}$ Here, the predictable nature of the sequel (something criticised by mainstream critics) is seen as being enhanced by 3-D, in giving an unusual sheen to the known visual pleasures and expectations. As noted in Starburst, 'the novelty value of watching all those gore scenes we have come to know and love so well in an added dimension does go a long way in making the routine suspense and scares more palatable.' This suggests that different taste cultures were now able to gain (at least marginal) critical representation through these new publications, offering a more positive appreciation of popular (and niche) film series and sequels, and promoting the opportunities offered by 3-D rather than simply rejecting the technology. This was not a wholesale endorsement of the technology, or the films produced: these magazine critics were as vocal in pointing out the problems with stereoscopic films as their mainstream counterparts. Yet rather than insist 3-D be abandoned, the tendency in such magazines was to demand that 
filmmakers should explore 'the maximum potential of the medium' to frighten audiences or to "have relevance to the story. ${ }^{, 77}$

The expansion of critical perspectives (and cultural hierarchies) suggested by the film magazine reviews is important in that it demonstrates that (unlike the 1950s), the British reception of 3-D in the 1980s allowed a wider range of critical perspectives on this divisive technology. Away from these more optimistic reviews, some mainstream critics were able to find positive elements of the 3-D aesthetic even while rejecting the overall technology. The use of 3-D graphic titles (an element added on to film in post-production, often using an optical printer) had been a feature of 3-D filmmaking in the 1950s, most effectively demonstrated in a series of 3-D film trailers released in $1953-4 .^{78}$ In the 1980 s films, such elements were most commonly seen in opening titles and credits: 'The 3D credit titles rocket out from the screen, seriously endangering the head of the person in front of you'; 'The audience... was plainly delighted by the opening titles which zoomed out at us from a skull's eye sockets. ${ }^{, 79}$ These titles, occurring before the actual film narrative begins (or after its conclusion), allowed such critics to enjoy the effect without having to consider their relationship with plot or character. The positive focus on this element, therefore, allowed the critic to enjoy an element of 3-D technology only where it existed outside of the traditional narrative space of the film; the sideshow attraction became acceptable where it preceded the film, not where it became part of the film's storytelling technique.

The focus on what 3-D added to (or detracted from) the cinema screen, particularly the critical emphasis on narrative and visual aesthetics, was, as in the 1950s, paralleled by one notable physical attribute: the polaroid glasses. As before, critical vitriol towards specific films was coloured by overwhelming dismissal of the cardboard glasses as an addition to the cinema viewing experience (notably, again, such 
criticisms never addressed actual audience opinion, simply critical dislike). Even with different films offering variations on design (Jaws 3-D featured a 'shark-shaped nosepiece') the dominant tone is dismissive: 'just when you thought it was safe to throw [away] your cardboard-rimmed stereoscopic spectacles'; 'silly paper spectacles'; 'Jaws 3D shamelessly props cardboard spectacles on to nose'; 'comic 3-D spectacles'; or 'paper polaroids. ${ }^{80}$ Gimmickry and 'coming at you' effects may have been rejected by some British critics, but polaroid glasses as a cinema experience was rejected by all. One absence from 1950s reviews of the glasses did become more commonplace in the 1980s, with the darkening of screen image caused by glasses and 3-D projection offering a (partial) reason for the critical dislike: '3-D... involves a loss of picture brilliance, the results here are often dark to the point of confusion,' 'the picture seemed unduly dark. ${ }^{, 81}$ This sense of a specific drawback to the 3-D technology that the glasses contributed to was unusual in the larger critical discourse (which tended to dismiss them as uncomfortable or flimsy), but one that has recurred in (and been developed by) $21^{\text {st }}$ century critics such as Mark Kermode, Roger Ebert and Jim Emerson, and filmmakers including Christopher Nolan and Edgar Wright. ${ }^{82}$

By 1984, 3-D technology was, once again, on the decline in British cinemas. From 1982, when Comin' at Ya! and Parasite had largely been limited to urban repertory sites such as London's ICA and Prince Charles cinemas, to 1984, with releases in larger cinema chains such as $\mathrm{ABC}$ and Odeon, 3-D distribution and exhibition remained a limited prospect. Future releases were scant and untested: Spacehunter: Adventures in the Forbidden Zone (Lamont Johnson, Columbia Pictures; Can/US, 1983) and Metalstorm: The Destruction of Jared-Syn (Charles Band, Hollywood Films; US, 1983) lacked the franchise possibilities of Jaws or Amityville 3$D .{ }^{83}$ By the middle of 1984 , although 3-D films continued to be exhibited in regional 
and local cinemas, the technology had again failed to attain mainstream success. ${ }^{84}$ While critical opinion cannot be held up as the sole reason for this failure, the evidence demonstrates that the critical agenda was able to build on residual disdain for the process held over from the 1950s, with 1980s critics quick to brand 3-D as gimmickry and intrusive, not a useful addition to the cinema experience. Although more genrebased film magazines claimed a particular enjoyment of what 3-D added to the known pleasures of sequels such as Jaws 3-D and Friday the $13^{\text {th }}$ Part III, the association with genre cemented an assumption that 3-D was only applied within a limited generic field: horror, science fiction, and western films (ignoring the wider genres in the 1950s). These attributes, expanding and reinforcing dominant ideas about the 3-D technology, and its lack of artistic endeavour, reiterated David Castell's view that this 3-D revival had been 'the biggest headache (literally) of 1983. ${ }^{85}$

\section{Conclusion}

3-D has never been the future of cinema. It is, was, and always will be the past. $^{86}$

This recent dismissal of 3-D by Mark Kermode, in newspaper articles, online, in regular radio broadcasts, and in book form, is an extension of the British critical reception around stereoscopic technology that this article has traced back through the last six decades of film criticism. ${ }^{87}$ Examining the reception trajectory of 3-D as a cinema technology since 1951 has revealed that critical language, and critical agendas, have remained constant, focused on the aesthetic limitations of the technology rather than its artistic possibilities. The opening epigraph from Raymond Spottiswoode, where 
artistry and technology were described as separate components of the popular discourse around 3-D, has been demonstrated by a discernible split in critical commentary between visual narratives and visual display, immersive story and sideshow attraction, realism and spectacle. 3-D technology has, through critical language, been used to dismiss the artistic sensibilities of filmmakers: 3-D is 'a dead giveaway, an unmistakable signal that the filmmakers are barren of ideas and reduced to gimmickry, ${ }^{88}$

The article has demonstrated how critical reviews have worked to set the agenda around 3-D technology, honing the range of opinions and perspectives down to a repetitive and dominant series of ideas that displace artistry in favour of gimmickry and fairground novelty. The reiteration of such similar language and rhetoric over these time periods has arguably formed a 'final moment,' a consolidation of critical opinion around 3-D technology: consistent references to novelty values, limited aesthetic tropes, reliance on 'coming at you' imagery, hatred of polaroid glasses, and a focus on restrictive generic productions. ${ }^{89}$ The British newspapers and film magazines covered here reinforced this 'final moment' with each successive 3-D film commentary, restricting competing discourses and framing the discussion in familiar ways. Such critics and reviewers have also defined 3-D as a recurrent historical failure, an unwanted tangent within film history that keeps coming back for successive sequels, but reliably banished each time.

This critical framework can be seen at work in a more recent example of British 3-D filmmaking: Street Dance 3-D (Max Giwa/Dania Pasquini, Vertigo Films; UK, 2010). According to British critics, the stereoscopic technology makes 'dance bounce off the screen,' 'throws a hat in your face' and contains 'a full-on foodfight (something of an inevitability in 3D films). ${ }^{90}$ There is also a suggestion that the film can be 
defined in generic terms, linking its appeal to a (fantasy) version of Singin' in the Rain (Stanley Donen/Gene Kelly, MGM; US, 1952) that would inevitably include 'Gene Kelly poking an umbrella in your eye or Donald O'Connor in your lap. ${ }^{91}$ Critics also pointed out Street Dance 3-D's simplistic narrative: ‘the script is so leprous with banalities it hurts your ears,' is a 'hackneyed girl-meets-boy story' and relies on 'stereotypes and stock situations. ${ }^{92}$ Modern reviews also draw the connection between 3-D and juvenilia: the film is described as 'mainlining Fanta,' 'hitting the tween bullseye,' being 'teen entertainment,' with the 'likely audience... much less critical' than the film reviewers who are likely ' 100 years too old to get this film. ${ }^{, 93}$ Yet, as with the 1980s film magazines discussed above, there are suggestive observations that could yet challenge this dominant 3-D discourse. The film's 3-D aesthetic 'comes alive in the showcase showdowns,' is 'bright and deep' and 'state-of-the-art. ${ }^{94}$ However, even in these cases, 3-D is largely described as an 'effect,' contributing to dance set-pieces and standing outside of the narrative, rather than an intrinsic part of it.

The modern digital 3-D experience may yet demonstrate more staying power than the 1950 s or 1980 s examples above. If it does, a more concerted consideration of 3-D technology, and the aesthetic opportunities it offers, could still challenge the critical dominance identified here. While it is not the purpose of this article to proselytise for 3D film or make any claims for its artistic status, it does call for wider engagement within the academy with stereoscopic media, past and present. The preceding analysis is simply one approach within this field: there are international contributions to 3-D films from countries such as Hungary, Russia, Canada and Japan, examples of 3-D television, 3-D animation, silent and early sound 3-D films. And that is simply looking to the past. The previous reference to stereoscopic 'media' is deliberate, and highlights the modern situation where 3-D is no longer defined as being in direct competition with 
other audio-visual technologies (television in the 1950s, home video in the 1980s).

With $21^{\text {st }}$ century 3-D existing across media, it may not be enough to reduce it to a passing gimmick, but to examine the true technical and artistic possibilities of this technology.

Keith M. Johnston, School of Film \& Television Studies, University of East Anglia, Norwich, Norfolk, NR4 7TJ

keith.johnston@uea.ac.uk

Work tel: 01603592274

Mobile tel: 07739552587

\footnotetext{
${ }^{1}$ Raymond Spottiswoode, 'Stereoscopic Films: A Chance to Experiment,' 1951 Edinburgh Film Festival materials, National Library of Scotland, File Acc 11308 / Box 9, file 32: 9.

${ }^{2}$ R.M. Hayes' 3-D Movies: A History and Filmography of Stereoscopic Cinema (Jefferson, NC, McFarland \& Company, 1989) and Ray Zone's Stereoscopic Cinema and the Origins of 3-D Film (Lexington, University Press of Kentucky, 2007) are solid historical introductions; while Hal Morgan and Dan Symmes' Amazing 3-D (Boston, Little, Brown \& Co., 1982) and Ray Zone's 3-D Filmmakers: Conversations with Creators of Stereoscopic Motion Pictures. Oxford, Scarecrow Press, 2005) are more journalistic in nature.

${ }^{3}$ Roger Ebert, 'D-minus for 3-D' Chicago Sun-Times (August 16), http://blogs.suntimes.com/ebert/2008/08/dminus_for_3d.html (accessed June 10 2009)

${ }^{4}$ Robert C. Allen \& Douglas Gomery, Film History: Theory and Practice (New York, Albert A. Knopf, 1985), p. 90.

${ }^{5}$ Barbara Klinger, Melodrama and Meaning: History, Culture and the Films of Douglas Sirk (Bloomington, Indiana University Press, 1994); Ernest Mathijs, 'Bad reputations: the reception of "trash" cinema,' Screen 46, 4 (2005), pp. 451-72.

${ }^{6}$ Klinger, Melodrama and Meaning, p. 69-70.

${ }^{7}$ Klinger, Melodrama and Meaning, p. 69.

${ }^{8}$ See, for example, Charles Barr, 'CinemaScope and After,' Film Quarterly 16, 4 (Summer 1963), pp. 4 24, including a riposte to Andre Bazin's discussion of widescreen, or John Belton, Widescreen Cinema (Cambridge, Harvard University Press, 1992).

${ }^{9}$ The film exhibitor's reaction to 1950s British 3-D has been discussed elsewhere, but the larger critical response remains unexplored: Keith M. Johnston, 'Now is the time (to put on your glasses): 3-D Film Exhibition in Britain, 1951-55,' Film History 23, 1 (2011), pp. 93-103.

${ }^{10}$ Mathijs, 'Bad reputations,' p. 451-2.

${ }^{11}$ Mathijs, 'Bad reputations,' p. 435.

12 The films were produced by a group of British technicians (notably Leslie Dudley, Spottiswoode and Charles Smith), in association with animators Norman MacLaren and John Halas, the Pathé Documentary Group and International Realist. Johnston, 'Now is the time (to put on your glasses.'

${ }^{13}$ Distant Thames and Royal River are different versions of the same film: Distant Thames was an incomplete cut of the stereoscopic footage, prepared for the Festival of Britain screenings when the producers ran out of time; Royal River, the finished cut of the full filmed material, debuted at the 1951 Edinburgh Film Festival.

${ }^{14}$ Laura Burd Schiavo, 'From Phantom Image to Perfect Vision: Physiological Optics, Commercial Photography and the Popularization of the Stereoscopic,' in Lisa Gitelman and Geoffrey B. Pingree (eds.), New Media, 1940-1915 (London: MIT Press, 2003), pp. 113-37.
} 
${ }^{15}$ Quotations from Laura Burd Schiavo, 'From Phantom Image to Perfect Vision,' pp. 128-9.

${ }^{16}$ Several attempts had been made to launch stereoscopic films ahead of the 1950s 'boom,' including short experiments by the Lumiere Bros, a feature film The Power of Love (1922), MGM's 'Audioscopiks' series (1936-41), a Polaroid system developed for the 1939 New York Worlds' Fair, and a 1940s Russian 'lenticular' system that did not require the use of spectacles. The $1950 \mathrm{~s}$ is commonly regarded as the first concerted commercial expansion and exploitation of the technology.

${ }^{17}$ Chapman Pincher, 'Is This Super Cinema the Model for the Future?' Daily Express (1 May 1951), p. 3; J.A.W., 'Stereoscopy and the Cinema,' The Scotsman (18 August 1951); Donald Zec, 'Specs make these films come to life,' Daily Mirror (1 May 1951), p. 6.

${ }^{18}$ J.A.W., 'Stereoscopy and the Cinema'; 'What to see at the South Bank - 4,' Daily Mirror (11 May 1951, p. 3.

19 'What to see at the South Bank - 4,' p. 3; Forsyth Hardy, 'The New Dimension in Films,' The Listener (6 September 1951), p. 370; American critics made similar observations: 'Distant Thames... is an essay in realism... The scenery, reproduced in delightfully subdued colour, had 3-dimensional depth... the spectator actually felt that by leaning slightly forward it would be possible to stroke the swans on the Thames.' (Gerard Pratley, 'The Latest 3-Dimensional Films,' Films in Review 3, 4 (April 1952), p. 174).

${ }^{20}$ Reviews of McLaren's films are largely restricted to Monthly Film Bulletin and Mini-Cinema.

${ }^{21}$ British 3-D commercials for Capstan Cigarettes (The Real Thing, 1953) and Kellogg's Cornflakes were equally absent from critical commentary.

${ }^{22}$ Pincher, 'Is This Super Cinema the Model for the Future?' p. 3; Zec, 'Specs make these films come to life,' p. 6.

23 'The Stroller,' 'Long Shots,' Kinematograph Weekly (15 March 1951), p. 5. See also R. Howard Cricks, 'Do We Want That Third Dimension?' Picturegoer (September 15 1951), p. 19 - where stereoscopic 3-D was also described as 'an old system' that had been 'keeping filmdom guessing for many years.'

${ }^{24}$ British producers Stereo Techniques (the company formed by Spottiswoode, Smith, Jack Ralph and Ken Nyman) claimed to have developed advanced stereoscopic technology, but noted similarities between their equipment and that used for a stereoscopic experiment at the 1939 New York World's Fair. Both were based on existing stereoscopic theory. (Spottiswoode 1951)

25 'The Stroller,' 'Long Shots,' (15 March 1951), p. 5.

26 'The Stroller,' 'Long Shots,' (15 March 1951), p. 5.

${ }^{27}$ Cricks, 'Do We Want That Third Dimension?,' p. 19; R. Howard Cricks, 'Stereoscopy - Is it here to stay or is it a Nine-Day Wonder?' The Ideal Kinema 18, 207 (12 June 1952), p. 19.

${ }^{28}$ For more on the British 3-D films success, see Johnston, 'Now is the time (to put on your glasses.'

29 'New Looks for Gold,' Kinematograph Weekly 414, 2306 (6 September 1951), p. 4; Onlooker, 'Up and Down the Street,' Today's Cinema 78, 6511 (26 May 1952), p. 4; 'An expert looks at Three-D'

Edinburgh Evening Dispatch 21,030 (April 3 1953), p. 6.

30 'First Full Length Venture in Three Dimensions: 'Bwana Devil" Comes to Glasgow,' Glasgow Herald 171, 63 (16 March 1953), p. 3g.

${ }^{31}$ Onlooker, 'Up and Down the Street,' p. 4; 'Gloomy...but among the greats,' Edinburgh Evening Dispatch, 20,848 (2 September 1952), p. 10.

${ }^{32}$ Reg Whitley, 'The Funeral of Flat Films,' Daily Mirror (17 February 1953), p. 2; Francis Raymond, 'House of Wax,' ABC Film Review (October 1951), p. 16.

33 'Glasgow Cinemas: The Charlatan, The Mute, and the Girl,' Glasgow Herald 171, 189 (10 August 1953), p. 3h; Frad Majdalany, 'Here's 3-D the Hard Way,' Daily Mail (21 March 1953), p. 4; Gavin Lambert, 'House of Wax, Man in the Dark and Bwana Devil,' Sight and Sound 23, 1 (July 1953), p. 31.

34 'A Day in the Country review, Monthly Film Bulletin 20, 233 (June 1953), p. 92; 'House of Wax review,' Monthly Film Bulletin 20, 234 (July 1953), p. 84.

35 'Inferno review,' Sunday Dispatch (27 September 1953); 'Kiss Me Kate review,' Sunday Dispatch (21 February 1954). Both sourced via BFI microjacket.

${ }^{36}$ Spottiswoode, 'Stereoscopic Films: A Chance to Experiment,' p. 10.

37 'Shirley Booth is worth her Oscar,' Edinburgh Evening Dispatch 21,051 (28 April 1953), p. 11.

38 'Bwana Devil review,' Monthly Film Bulletin 20, 232 (May 1953), p. 65.

39 'Great Potentialities of 3-D Technique: Flaws of Immaturity in "Bwana Devil",' Glasgow Herald 171, 69 (23 March 1953), p. 5f; 'Hondo review,' Daily Mail (28 February 1954), Hondo BFI microjacket;

'The Charge at Feather River review,' Monthly Film Bulletin 20, 238 (November 1953), p. 158; 'ThreeD adds beauty and point to Western,' Edinburgh Evening Dispatch 21,272 (12 January 1954), p. 11.

40 'Future for 3-D? It's Doubtful,' Edinburgh Evening Dispatch 21,019 (21 March 1953), p. 18. 
41 'Edinburgh gets a taste of 3-D,' Evening Dispatch 21,036 (10 April 1953), p. 14; Newell Rogers, 'A kiss out of the picture,' Daily Express (29 November 1952), p. 2; 'Glasgow Cinemas,' p. 3h; 'Chiefly Fightin', Fuedin', A'Fussin,' Edinburgh Evening Dispatch 21,440 (27 July 1954), p. 11; 'Kiss Me Kate review,' Financial Times (1 March 1954), BFI microjacket.

${ }^{42}$ 'First Full Length Venture in Three Dimensions,' p. 3g.

${ }^{43}$ Irving, '3-D starts 7000 Arguments,' p. 6. See also, Tanfield, 'Tanfield's Diary: 3-D plus,' Daily Mail (18 April 1953), p. 4; 'Bwana Devil review,' Monthly Film Bulletin 20, 232 (May 1953), p. 65; 'Man in the Dark review,' Today's Cinema 80, 6736 (14 Apr 1953), p. 8:

${ }^{44}$ 'Future for 3-D? It's Doubtful,' p. 18.

45 'Around the Cinemas: Three-D Conversion at the Critics Request,' Edinburgh Evening Dispatch 21,320 (9 March 1954), p. 11.

${ }^{46}$ 'Three-D adds beauty and point to Western,' p. 11.

${ }^{47}$ B. Baxter, 'A portent,' Evening Standard (12 November 1953), BFI microjacket; 'It's not another Shane - but almost' Edinburgh Evening Dispatch 21,422 (6 July 1954), p. 11.

48 'Dial M for Murder review,' Daily Star (16 July 1954), BFI microjacket.

49 'Dial M for Murder review,' Sunday Times 18 July 1954), BFI microjacket.

${ }^{50}$ Pincher, 'Is This Super Cinema the Model for the Future?' p. 3.

${ }^{51}$ Keith Waterhouse, Keith, 'Slap it on, Edward!' Daily Mirror (10 April 1952), p. 2; 'Hollywood Speedy Reply to Challenge of Television,' Daily Mirror (10 February 1953), p. 9; Whitley, 'The Funeral of Flat Films,' p. 2

52 'Sangaree review,' Edinburgh Evening Dispatch 21,165 (8 September 1953), p. 2; Majdalany,

“'Here's 3-D the Hard Way,' p. 4; 'Bwana Devil review,' p. 65; Leonard Mosley, 'Focal No. 1 Just Made My Head Ache,' Daily Express (21 March 1953), p. 3.

${ }^{53}$ The glasses were also an issue for film exhibitors, many of whom had to pay tax on the glasses. See Johnston, 'Now is the time (to put on your glasses.'

${ }^{54}$ This critical dismissal of glasses was at the heart of CinemaScope's advertising campaigns, which promised an immersive film experience that didn't require 'special glasses.' For more on the technological competition between 3-D and CinemaScope in the 1950s, see Keith M. Johnston, Coming Soon: Film Trailers and the Selling of Hollywood Technology (Jefferson, NC: McFarland \& Company, 2009).

55 'An expert looks at Three-D,' p. 6.

56 'The Stewardesses review,' Variety 260, 5 (16 September 1970), p. 24.

${ }^{57}$ Bill Warren, '3-D Movies / Parasite,' Starburst 4, 11 (July 1982), pp. 52-55.

${ }^{58}$ Peter Haigh, 'Big Technical Advance Makes Way for Return of 3-D Films,' Film Review (September 1982), pp. 36-7.

${ }^{59}$ Patrick Gibbs, 'Jaws 3-D review,' Daily Telegraph (16 December 1983), p. 11; Ian Bell, 'Jaws goes flat in three dimensions,' The Scotsman (10 December 1983), p. 3; 'Cinema: New Releases,' City Limits 84 (13-19 May 1983), p. 26.

${ }^{60}$ Haigh, 'Big Technical Advances Makes Way for Return of 3-D Films,' p. 37. Critic Patrick Gibbs did note the presence of Alfred Hitchcock's Dial M For Murder in his brief overview of 3-D history, but there was little sense that an auteur figure - often used as a mark of cultural significance - could be used to claim artistic relevance for the 3-D process: Gibbs, 'Jaws 3-D review,' 11.

${ }_{61}^{6}$ Jaws 3-D Production Notes, p.2 (BFI microjacket)

62 'Jaws 3-D review,' Monthly Film Bulletin 50, 599 (December 1983), p. 330; David Robinson, 'Jaws 3 $D$ review' The Times (16 December 1983), p. 10.

63 'Comin' at Ya! review,' Monthly Film Bulletin 49, 583 (August 1982), p. 166.

${ }^{64}$ David McGillivray, 'Comin' at Ya!' Films and Filming 335 (August 1982), p. 31.

${ }^{65}$ McGillivray, 'Comin' at Ya!' p. 31; Cynthia Rose, 'Comin' At Ya,' City Limits 39 (2-8 July 1982), p. 4.

${ }_{66}^{66}$ Alan Jones, 'Parasite review' Starburst 4, 12 (August 1982), pp. 16-17.

${ }^{67}$ Nigel Andrews, 'Jaws $3 D$ review' Financial Times (16 December 1983), p. 21; Alexander Walker,

'Another fin mess' Evening Standard (15 December 1983), p. 21.

${ }^{68}$ Neil Sinyard, 'Amityville 3-D,' Films and Filming 355 (August 1984), p. 31.

${ }^{69}$ Robinson, 'Jaws 3-D review' p. 10.

${ }^{70}$ Iain Johnstone, 'Jaws III-D review' Sunday Times (18 December 1983), p. 43.

${ }^{71}$ Arthur Thirkell, 'Jaws 3-D review' Daily Mirror (16 December 1983), p. 19.

${ }^{72}$ Robinson, 'Jaws 3-D review,' p. 10. 
${ }^{73}$ Rose, 'Coming' At Ya!' p. 4; Cynthia Rose, 'Coming at Ya review,' Monthly Film Bulletin 49, 582 (July 1982), p. 135; Brian Baxter, 'Jaws 3D' Films and Filming 352 (January 1984), p. 36; Nick

Roddick, 'Jaws 3-D review’ Monthly Film Bulletin 50, 599 (December 1983), p. 330.

${ }^{74}$ Gibbs, 'Jaws 3-D review,' p. 11; Kim Newman, 'Amityville 3-D review' City Lights 137 (18-14 May 1984), p. 30.

${ }^{75}$ Bell, 'Jaws 3-D review,' p. 3.

76 'Friday the $13^{\text {th }}$ review,' Starburst 58 (June 1983), p. 38; ' $3^{\text {rd }}$ Helpings of Horror,' Film Review 33, 6 (June 1983), p. 14.

77 'Friday the $13^{\text {th }}$ review,' p. 38; 'Jaws 3-D review,' Film Review 34, 1 (January 1984), p. 28.

${ }^{78}$ Johnston, Coming Soon: Film Trailers and the Selling of Hollywood Technology pp. 41-2.

${ }^{79}$ Andrews, 'Jaws 3-D review,' p. 21; David McGillivray, 'Friday the $13^{\text {th }}$ Part III 3-D,' Films and Filming 348 (September 1983), p. 34.

${ }^{80}$ Virginia Dignam, 'Jaws 3-D review,' Morning Star (16 December 1983, p. 2; David Castell 'Jaws 3-D review,' Sunday Telegraph (18 December 1983), p. 12; Bell, 'Jaws 3-D review,' p. 3; John Coleman, 'Jaws 3-D review' New Statesman (16 December 1983), p. 32; Margaret Hinxman, 'Jaws 3-D review,' Daily Mail (16 December 1983), p. 22; Andrews, 'Jaws 3-D review,' p. 21.

${ }^{81}$ Castell, 'Jaws 3-D review,' p. 12; Gibbs, 'Jaws 3-D review,' p. 11.

${ }^{82}$ Mark Kermode, 'No, your eyes aren't deceiving you - 3D really is a con,' The Observer (11 April 2010), http://www.guardian.co.uk/commentisfree/2010/apr/11/3d-avatar-hollywood; Roger Ebert, 'Why I Hate 3-D (And You Should Too), Newsweek (9 May 2010),

http://www.thedailybeast.com/newsweek/2010/04/30/why-i-hate-3-d-and-you-should-too.html; Mike Eisenberg, 'Christopher Nolan Talks 3-D, IMAX and "Inception”,' http://screenrant.com/christophernolan-talks-3d-imax-inception-mikee-50838/; 'Edgar Wright - Scott Pilgrim Director No 3-D Fan,' http://www.contactmusic.com/news/scott-pilgrim-director-no-3d-fan_1158652.

${ }^{83}$ Few reviews exist for these films, particularly 3-D screenings of them. Film Review reduced 3-D to a 'special effect' in Treasure of the Four Crowns and describing Metalstorm as 'comic strip... great stuff for kids,' connecting gimmickry with visual spectacle and not immersive narrative. 'A Pair of 3-D Spectacles,' Film Review 33, 7 (July 1983), p. 27; 'Metalstorm review,' Film Review 34, 4 (April 1984), p. 35.

${ }^{84}$ The author knows of at least one screening of Jaws 3-D in Sleaford, Lincolnshire, circa 1987, likely on a re-run circuit. However, this points to the difficulty of identifying a date at which the 1980s 'boom' ended for British audiences. Adverts for Spacehunter note that it was playing in 3-D in 'some cinemas': Spacehunter advert, Film Review 33, 12 (December 1983), p. 35.

${ }^{85}$ Castell, 'Jaws 3-D review,' p. 12.

${ }^{86}$ Mark Kermode, 'No, your eyes aren't deceiving you'.

${ }^{87}$ Kermode regularly appears with Simon Mayo on BBC Five Live, on the BBC blogs, in The Observer, on Twitter, and talks about 3-D in his 2011 book The Good, the Bad and the Multiplex (London: Random House).

${ }^{88}$ Bell, 'Jaws 3-D review,' p. 3.

${ }^{89}$ Mathijs, 'Bad reputations,' p. 435.

${ }^{90}$ Allan Hunter, 'Streetdance film review,' Daily Express (21 May 2010), http://www.express.co.uk/entertainment/view/176399/Streetdance-3D-Film-review-and-trailer-; Simon Crook, 'Streetdance 3-D,' Empire May 2010,

http://www.empireonline.com/reviews/ReviewComplete.asp?FID=136806; Catherine Shoard, 'StreetDance 3-D,' The Guardian 20 May 2010, http://www.guardian.co.uk/film/2010/may/20/streetdance-3d-review (all reviews accessed 4th March 2011)

${ }^{91}$ Hunter, 'Streetdance film review.'

${ }^{92}$ Anthony Quinn, 'Streetdance 3-D,' The Independent 21 May 2010, http://www.independent.co.uk/artsentertainment/films/reviews/streetdance-3d-pg-1978588.html; Chris Tookey, 'Let the Dancers Do Their Stuff,' The Daily Mail 21 May 2010, http://www.dailymail.co.uk/tvshowbiz/reviews/article1280056/Streetdance-3D-Let-dancers-stuff.html; AJ, 'Streetdance,' Radio Times, http://www.radiotimes.com/servlet_film/com.icl.beeb.rtfilms.client.simpleSearchServlet?searchTypeSele $\mathrm{ct}=5 \& \mathrm{frn}=49744$ (reviews accessed $4^{\text {th }}$ March 2011$)$

${ }^{93}$ Crook, 'Streetdance 3-D'; Hunter, 'Streetdance film review'; Tookey, 'Let the Dancers Do Their Stuff'; Quinn, 'Streetdance 3-D.'

${ }^{94}$ Shoard, 'StreetDance 3-D'; Crook, 'Streetdance 3-D'; Matthew London, 'Streetdance 3-D,' View London (19 May 2010), http://www.viewlondon.co.uk/films/streetdance-3d-film-review-33965.html (accessed 4th March 2011) 
Keith M. Johnston is a Lecturer in Film \& Television Studies at the University of East Anglia. His current research focuses on the interplay of technology, aesthetics and industry in British film of the 1940s and 1950s, particularly around issues of colour, widescreen and 3-D. His research has been published in the Journal of British Cinema and Television, Film History, the Journal of Popular Film and Television, Film International and Convergence. He is the author of Coming Soon: Film Trailers and the Selling of Hollywood Technology (McFarland, 2009) and Science Fiction Film: A Critical Introduction (Berg, 2011) 